\title{
Acute aortic syndrome
}

\author{
Steven L. Lansman, MD, PhD, Paul C. Saunders, MD, Ramin Malekan, MD, and David Spielvogel, MD
}

The term acute aortic syndrome refers to a heterogeneous group of conditions that cause a common set of signs and symptoms, the foremost of which is aortic pain. Various pathologic entities may give rise to this syndrome, but the topic has come to focus on penetrating aortic ulcer and intramural hematoma and their relation to aortic dissection. Penetrating aortic ulcer is a focal atherosclerotic plaque that corrodes a variable depth through the intima into the media. Intramural hematoma is a blood collection within the aortic wall not freely communicating with the aortic lumen, with restricted flow. It may represent a subcategory of aortic dissection that manifests different behavior by virtue of limited flow in the false lumen. This article reviews the current literature regarding acute aortic syndrome, focusing on management options. ( $\mathrm{J}$ Thorac Cardiovasc Surg 2010;140:S92-7)

The term acute aortic syndrome (AAS), coined by Vilacosta and associates ${ }^{1,2}$ in 1998 , refers to a heterogeneous group of conditions that cause a common set of signs and symptoms, the foremost of which is aortic pain. The pain is acute, severely intense-often maximally so at its outset-and may be described as tearing, ripping, migrating, or pulsating. Hirst, Johns, and Kime ${ }^{3}$ state: "The patient will frequently volunteer the information that it feels as if 'something has broken loose' in the chest.' Various diseases may cause this striking presentation, including trauma, pseudoaneurysm, and ruptured atherosclerotic aneurysm, but the term has come to subsume penetrating aortic ulcer (PAU), intramural hematoma (IMH), and aortic dissection (AD). One might ask whether a special category is needed for these entities, but the term does seem to serve a function; like "acute coronary syndrome" and "acute abdomen," it isolates a set of pathologic conditions that may be unrelated etiologically but nonetheless have a similar presentation and require emergency attention.

\section{PENETRATING AORTIC ULCER (PAU)}

PAU, initially described by Shennan ${ }^{4}$ in 1934 , is a focal atherosclerotic plaque that corrodes a variable depth through the internal elastic lamina into the media. It may form a pseudoaneurysm or may rupture into the media, forming an IMH in the media ${ }^{5,6}$ or between the media and adventitia. ${ }^{4,6,7}$ The hematoma may propagate locally or, rarely, may give rise to classic AD.

PAUs tend to occur in older men. ${ }^{8-10}$ The lesions may be single or multiple $(31.6 \%$ in the series reported by Botta

\footnotetext{
From Westchester Medical Center, New York Medical College, Valhalla, NY.

Disclosures: David Spielvogel is a consultant for Magurt and is a member of the speakers bureau for Vascutek Terumo. Steven L. Lansman, Paul C. Saunders, and Ramin Malekan have nothing to disclose with regard to commercial support.

Received for publication April 27, 2010; revisions received July 20, 2010; accepted for publication July 26, 2010.

Address for reprints: Steven L. Lansman, MD, PhD, Westchester Medical Center, Department of Surgery, Macy Pavilion 114W, Valhalla, NY (E-mail: LansmanS@WCMC.com).

0022-5223/\$36.00

Copyright (c) 2010 by The American Association for Thoracic Surgery doi:10.1016/j.jtcvs.2010.07.062
}

and associates ${ }^{11}$ ), are predominantly situated in the descending aorta, ${ }^{9,12}$ but less frequently occur in the $\operatorname{arch}^{1,13-15}$ or abdominal ${ }^{15,16}$ segments, and rarely in the ascending aorta. ${ }^{1,8,13-15}$ In the Mayo Clinic series, ${ }^{8}$ patient characteristics included hypertension ( $92 \%)$, tobacco use $(77 \%)$, and coronary artery disease (46\%); $75 \%$ were symptomatic, usually with back pain, and $30 \%$ had pleural effusions. Chronic obstructive pulmonary disease is common ( $24 \%$ in the Mayo series $^{8} ; 68.4 \%$ in Botta and associates' series ${ }^{11}$ ), as are concurrent aneurysms, particularly in the abdomen $(42.1 \%$ in the Yale series ${ }^{10} ; 61 \%$ in the Mayo series ${ }^{8}$ ).

PAU is best diagnosed by contrast-enhanced computed tomographic (CT) scan or magnetic resonance imaging, appearing as a focal, contrast-filled outpouching with irregular margins, and extending beyond the expected aortic wall boundaries. It generally occurs in the presence of severe atheromatous disease. ${ }^{5,17,18}$

The incidence of PAU in AASs ranges from $2.3 \%$ to $11 \% .{ }^{19}$ In Hirst and Barbour's comprehensive autopsy series, ${ }^{20} 4.6 \%$ (18/398) of dissections originated from PAUs. The prevalence of PAU is unknown but may be less than once suspected, inasmuch as the widespread use of coronary CT scans has not uncovered large numbers of incidental cases. ${ }^{21}$ One recent study revealed only 2 PAUs in 966 cardiac CT coronary angiograms, ${ }^{21}$ and another found but 1 PAU in 395 CTs obtained for suspected acute coronary syndrome. ${ }^{22}$

\section{Management of PAU}

Conflicting reports about the natural history of PAU have led to opposing management strategies. Concerned with the "potentially progressive and serious nature" of PAU, Stanson and his colleagues ${ }^{13}$ at the Mayo Clinic in 1986 initially adopted an aggressive stance, but their approach changed as conservative therapy proved successful ${ }^{23}$ : in 105 cases, 30day mortality for medical and surgical treatment was $4 \%$ and $21 \%(P<.05)$. Moreover, in $89 \%$, mean IMH thickness decreased by 1 month, completely resolving by 1 year in $85 \%$, and only 6 patients needed late surgery for aortic expansion. ${ }^{8}$ Hussain and associates ${ }^{24}$ also reported a benign course for PAU in 5 patients: although 4 were symptomatic, all survived without surgery, with complete resolution in 4 . 


\section{Abbreviations and Acronyms \\ $\mathrm{AAS}=$ acute aortic syndrome \\ $\mathrm{AD}=$ aortic dissection \\ $\mathrm{CT}=$ computed tomography \\ $\mathrm{IMH}=$ intramural hematoma \\ PAU $=$ penetrating aortic ulcer \\ $\mathrm{ULP}=$ ulcer-like projection}

A CT study evaluating 56 PAUs in 38 patients did not reveal any feature predictive of lesion progression, although pleural effusion did correlate with clinical instability. ${ }^{15}$ Only $30 \%$ progressed, manifesting a mild-moderate increase in lesion size, aortic diameter, or both, whereas $76 \%$ were asymptomatic, with clinically stable lesions. Thus, on the basis of satisfactory results with a conservative approach, a number of authors have recommended initial supportive therapy for PAU, with surgery reserved to treat or prevent rupture, as indicated by persistent pain or enlarging PAU or aortic size.

PAU proved less benign in other series. For example, Harris and colleagues, ${ }^{16}$ monitoring 17 ulcers in 10 patients, reported distal embolization in 1 and progression to fusiform or saccular aneurysm formation in $12 \%$ and $29 \%$. The Yale group reported that $40 \%$ of 15 medically managed patients needed emergency surgery for rupture. ${ }^{14}$ An updated review of their series, showing rupture in $38 \%$, surgical intervention in $65 \%$, and hospital mortality in $15 \%$, reinforced their advocacy of aggressive management for PAU. ${ }^{25}$ The Stanford group also advocated an aggressive approach on the basis of their experience with 65 IMH cases, wherein progression with and without PAU was $48 \%$ and $8 \%$ and medical management resulted in $10 \%$ mortality. ${ }^{26}$ Predictors of progression included sustained or recurrent pain $(P<.0001)$, increasing pleural effusion $(P=.0003)$, and both the maximum PAU diameter $(P=.004)$ and maximum PAU depth $(P=.003)$, with recommended threshold values of $20 \mathrm{~mm}$ for PAU diameter and $10 \mathrm{~mm}$ for PAU depth.

\section{Endovascular Treatment of PAU}

Whether PAUs are initially treated more or less aggressively, both camps advocate intervention for clear-cut indications of pending or actual rupture, and over the past decade endovascular treatment has emerged as an attractive option. PAU comprised $7.1 \%$ of a series of 113 consecutive patients with acute disease in the Talent Thoracic Retrospective Registry. ${ }^{27}$ One might think endograft therapy an attractive setting for PAU, inasmuch as most are isolated and localized in a relatively normal-sized aorta, but there are a number of caveats. First, PAU occurs in an older group having significant comorbidities, often including chronic obstructive pulmonary disease, coronary artery disease, and renal insufficiency. Also, apparently isolated PAUs often arise in a diffuse atherosclerotic setting, which may increase the incidence of type I endoleaks- $-18 \%$ in a recent series. ${ }^{11}$ Luminal irregularity may therefore necessitate more extensive endografting than anticipated and-as opposed to atherosclerotic aneurysms, where intercostal branches are often thrombosed-intercostal vessels may be patent in PAU, increasing the risk of paraplegia by endograft occlusion. ${ }^{12}$

Nonetheless, endograft treatment of PAU has yielded excellent perioperative results for these high-risk patients. The Stanford group reported $94 \%$ primary success in 26 patients, with $12 \% 30$-day mortality and $0 \%$ paraplegia, although half of the PAUs were deemed inoperable and 6 were ruptured $^{7}$; however, underscoring the significance of comorbidities, the 5-year survival was only $70 \%$. Similarly, Botta and coworkers, ${ }^{11}$ with $0 \%$ intraoperative mortality in 19 cases, and Eggebrecht and colleagues, ${ }^{28}$ with $0 \% 30$-day mortality in 22 cases, reported 5-year survivals of $66.7 \%$ and $62 \%$. Criteria for endograft placement in the acute setting, advanced by Botta's group, ${ }^{11}$ include pain and rupture; in chronic cases, indications include recurrent pain, aortic diameter greater than $55 \mathrm{~mm}$, and increase in size greater than $10 \mathrm{~mm}$ per year.

\section{INTRAMURAL HEMATOMA (IMH)}

IMH, first described by Krukenberg ${ }^{29}$ in 1920 , has been described as "dissection without intimal tear." Histologically, the hematoma generally extends within the media, but it may be subadventitial. ${ }^{6}$ On diagnostic imaging, IMH appears as a smooth, crescentic, or circular thickening greater than 5 to $7 \mathrm{~mm}$. With expansion, the hematoma may encroach on the aortic lumen and, if intimal calcium is present, displace it centrally. Transthoracic or transesophageal echocardiography may demonstrate IMH, but multidetector CT is the best diagnostic modality, inasmuch as it can image the entire aorta and branch vessels. ${ }^{18}$

IMH comprises $10 \%$ to $30 \%$ of AAS. ${ }^{6}$ The patients tend to be older, ${ }^{10}$ and most are hypertensive. ${ }^{10,30-33}$ In the International Registry of Aortic Dissection database, IMH was more common in the descending aorta $(60.3 \%)$ than the ascending aorta $(39.7 \%)$. ${ }^{32}$ Type A IMH is often complicated by pericardial effusion $\left(47 \%{ }^{34}-68.3 \%{ }^{33}\right)$, pleural effusion $\left(49 \%{ }^{33}\right)$ and aortic insufficiency $\left(11.9 \%{ }^{33}-21 \%{ }^{34}\right)$. Interestingly, Marfan syndrome $(1 \%)^{33}$ and bicuspid aortic valve were uncommon in many series.

\section{Mechanism and Definition}

It is commonly held that $\mathrm{AD}$ arises from an intimal tear, whereas IMH arises from "rhexis" of the vasa vasorum, without an intimal tear. ${ }^{5}$ However, the issue has long been debated, and many hold that a single mechanism gives rise to both entities; some believe that IMH represents $\mathrm{AD}$ with a thrombosed false lumen, whereas others believe 


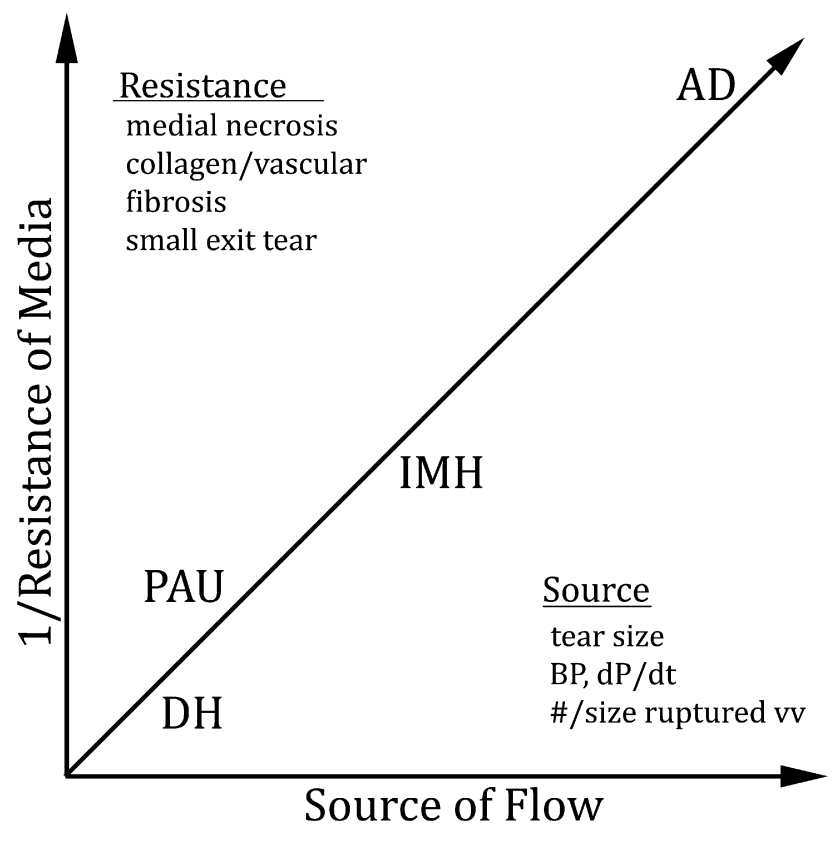

FIGURE 1. Relationship between flow, medial resistance, and aortic diseases. $D H$, Discrete hematoma; $I M H$, intramural hematoma; $P A U$, penetrating aortic ulcer; $A D$, acute dissection; $v v$, vasa vasorum; $B P$, blood pressure; $\mathrm{dP} / \mathrm{dt}$, rate of pressure rise.

IMH represents intramedial hemorrhage, without rupture into the true lumen. Hirst and associates, ${ }^{3}$ who found 21 (4\%) IMHs in their 1958 review of 504 AD cases, supported the latter theory, noting, "The concept of initiation of aortic dissection by rupture of the vasa vasorum is not new, having been favored by Krukenberg in 1920.' As evidence, they cited necropsy reports of hematomas without tears (and tears without hematomas) going back to 1936 . IMH may also arise from trauma, ${ }^{35}$ or rupture of a PAU into the media. 4

Krukenberg ${ }^{26,29}$ described IMH as "dissection without tear,' but a number of studies emphasize the prevalence of tears in supposed cases of IMH. For example, Park and colleagues $^{36}$ found intimal tears on retrospectively reviewed preoperative CTs in $48.6 \%$ of 37 cases and in $73 \%$ at surgery; in $67 \%$, the defects were located in the arch or distal ascending aorta, emphasizing the need to inspect the aorta during circulatory arrest. $^{37}$ Similarly, Svensson and coworkers ${ }^{38}$ described a localized, "discrete" hematoma that is difficult to image, inasmuch as it is associated with a small intimal tear; these lesions were found in $5 \%$ of a series of ascending and arch replacements ${ }^{38}$ and $7.3 \%$ of a series of type A ADs. ${ }^{39}$

Confounding the issue, intimal tears can arise secondarily, as derivative events in the development of an IMH. ${ }^{15,40}$ They may occur as the fragile, unsupported intimal layer is subjected to shear forces; alternatively, they may be caused by differential compliances of the outer and inner layers $^{38}$ or may represent a decompression mechanism for the expanding hematoma. ${ }^{6}$
Although authors may disagree on the role of intimal tears, it is widely held that disease of the media is necessary for propagation to occur. ${ }^{3,23}$ After all, worldwide, intimal tears are created during aortic cannulation in over 1 million cases annually, but rarely result in AD. Normal or fibrosed media may prohibit or retard $\mathrm{IMH}$ and $\mathrm{AD}$ propagation, whereas abnormal media, as in medial necrosis or Marfan syndrome, may potentiate propagation. Broadly speaking, propagation or flow in the media is governed by 2 factors: the magnitude of the source, be it vasa vasorum or an intimal tear, and the resistance to flow in the media (Figure 1). If, in concert, these factors yield restricted flow, then thrombosis occurs and a discrete hematoma or IMH ensues; conversely, a large source of blood with low medial resistance will result in AD.

The debate about IMH etiology may have shifted focus from its essential aspect, which is that restricted flow in the media gives rise to its characteristic behavior. ${ }^{33} \mathrm{~A}$ functional definition of IMH, from the perspective of flow, is that IMH is a blood collection within the aortic wall, not freely communicating with the lumen, with restricted flow. Thus, the epigram 'dissection without intimal tear' becomes " dissection with restricted flow." This definition of IMH has the virtue of removing the impossible task of proving a negative ${ }^{23}$ (the absence of an intimal tear) while focusing on a positive (flow in the false lumen) that probably bears more directly on its behavior.

\section{Incidence and Natural History of IMH}

Controversy regarding the natural history of IMH stems from very different experiences with the prognosis and even the incidence of IMH between centers in North America and Europe, and centers in Japan and Korea.

The incidence of IMH in the International Registry of Aortic Dissection database, ${ }^{32}$ comprising data from many Western centers, was 6\% (58/1010), whereas in 2 large recent Eastern series of type A AD, type A IMH comprised $28.3 \%{ }^{33}$ and $29 \% .^{41}$ A meta-analysis of international experience confirmed that the incidence of type A IMH is lower in North America/Europe (10.9\%) than in Japan/Korea $(31.7 \% ; P<.0001) .^{42}$

IMH is known to be a dynamic entity: it may regress, progress to classic $\mathrm{AD}$, expand, or rupture, and these tendencies also seem to vary geographically. For example, the Yale group observed resolution in $19 \%,{ }^{25}$ whereas a Korean study showed resorption in $67 \%(24 / 36)$ with type A IMH and $78 \%(54 / 69)$ with type B IMH. ${ }^{43}$ Similarly, reports of progression or malignity have tended to vary along EastWest lines. The Yale group reported expansion or rupture in $47.1 \%$ of 17 cases, with only $50 \%$ of patients surviving to hospital discharge, ${ }^{10}$ and a group of Western centers reported early progression in $45 \%$ of $66 \mathrm{IMH}$ cases, with $20 \%$ mortality, and late progression in $21 \%$, with $17 \%$ mortality. ${ }^{44}$ In Eastern series, the rate of progression was 
not necessarily less, but outcomes have been more favorable. For example, in a recent Japanese series of 50 type A IMH cases, early and late progression was $30 \%$ and $10 \%$, but the overall mortality was only $4 \% .^{41}$

\section{Management of IMH}

Divergent clinical experiences have led to contrasting recommendations for IMH management from Western and Eastern centers. The Stanford group, based on an early experience with 13 patients, recommended adopting the strategy used for AD: surgery for type A IMH and initial medical treatment for type B. ${ }^{30}$ Nienaber and associates ${ }^{45}$ reported that early mortality with and without surgery was $0 \%(0 / 7)$ versus $80 \%(4 / 5 ; P<.01)$; a group of Western centers reported $8 \%$ versus $55 \%(P=.004),{ }^{44}$ and a meta-analysis of 143 type A IMH cases from primarily (13/19) Western centers showed $14 \%$ versus $36 \%$ $(P<.02){ }^{31}$ In contrast, a recent meta-analysis of 328 cases of type A IMH from primarily (9/12) Asian centers showed no difference in early mortality between surgical $(10.1 \%$ $[17 / 168])$ and medical $(14.4 \%$ [23/160]) strategies $(P=.37){ }^{34}$ Also, the recent meta-analysis comparing Eastern versus Western reports for type A IMH yielded mortality rates of $9.4 \%$ versus $20.6 \%$, attributed in part to the lower mortality with early medical therapy $(7.8 \%$ vs $33.3 \% ; P<.0001)$. $^{42}$

Two recent large single-center Asian experiences support a conservative approach. Kitai and associates ${ }^{41}$ treated 50 of 66 patients with type A IMH (PAU and ulcer-like projection [ULP] excluded) with medical therapy plus "timely" surgery. Early mortality for the medical and surgical groups was $4 \%$ and $6 \%$. Thirty-two $(64 \%)$ were discharged without requiring surgery, with $0 \%$ late mortality related to IMH or delayed surgery. Follow-up CT scans, available in 31 , showed complete resolution in 30 , with significant reductions in maximum hematoma thickness $(9 \pm 4 \mathrm{~mm}$ to $0 \pm 1 \mathrm{~mm} ; P<.001)$ and aortic diameter $(45 \pm 4 \mathrm{~mm}$ to $42 \pm 6 \mathrm{~mm} ; P=.001)$. Survival at 1,5 , and 10 years was $96 \%, 94 \%$, and $89 \%{ }^{41}$ Another series, reporting 357 consecutive cases of type A AAS, described "timed" surgery in 101 type A IMH cases (PAU excluded). Sixteen unstable patients had emergency surgery, with $12.5 \%$ (2/ 16) mortality, and 85 received medical therapy, with $7.1 \%(6 / 85)$ hospital mortality. "'Timed"' surgery was performed on 17 before discharge and 8 after discharge, with $4 \%(1 / 25)$ overall mortality. Sixty-two $(80 \%)$ observed patients were discharged home without requiring surgery. Survival was the same for medical and surgical groups: $87.6 \%$ and $83.1 \%$ at 1 and 3 years. ${ }^{33}$ Although these results are quite good from a population standpoint, 6 patients with probably very low operative risk died suddenly while under observation. Of note in this regard is the recent Japanese report of 41 surgically treated patients with type A IMH, with $0 \%$ hospital mortality and $100 \%$ 5-year survival. ${ }^{46}$
Thus, a spectrum of IMH with restricted medial flow, thrombosis, and a more benign course occurs more frequently in the Asian population, but the divergence between Eastern and Western experiences has not been explained. In light of success with the Eastern approach, some Western centers are cautiously adopting a more conservative strategy. For example, Estrera and associates ${ }^{47}$ reported an intermediate approach with timely but not immediate surgery in 36 patients with type A IMH, from a series of 251 patients with acute type A AD. Immediate surgery was performed in 7 , with $14.3 \%$ (1/7) mortality, and 28 $(80 \%)$ underwent timely surgery, with $7.1 \%(2 / 28)$ mortality. During observation, 33\% (12/36) of type A IMHs converted to AD, but none within the first 72 hours. Of interest, the 1 medically managed patient - of Asian ethnicitysurvived, with full resolution. ${ }^{47}$ The authors believed that deferring emergency surgery permitted the aortic wall to thicken, facilitating repair, and allowed the extensive, acute inflammatory response to subside.

\section{Predictors of IMH Behavior}

A significant number of IMHs in series of "timed" or "timely" surgery progressed, in terms of expansion, AD, or death, permitting predictors of progression to be identified. For type B IMH, age older than 70 years and the appearance of ULPs strongly predicted progression. ${ }^{48}$ In Kitai and associates $^{\text {, }}{ }^{1}$ study of type A IMH, cardiac tamponade was a univariate risk factor and maximum hematoma thickness of $10 \mathrm{~mm}$ or more was identified as a cutoff for predicting progression, but only aortic diameter of $50 \mathrm{~mm}$ or more predicted progression by multivariate analysis. Aortic diameter of $55 \mathrm{~mm}$ or more was identified as a significant predictor of progression in Song and colleagues ${ }^{33}$ recent publication, as well as IMH thickness greater than $16 \mathrm{~mm}$.

Other ominous signs include persistent pain, the presence of PAU, ${ }^{41}$ the appearance of ULPs, ${ }^{33,41}$ malperfusion, ${ }^{33,47}$ and indications of proximal root involvement, including aortic insufficiency ${ }^{41}$ and a large pericardial effusion or cardiac tamponade. ${ }^{41}$

On the basis of these and similar studies, conservative criteria for initial observation of type A IMH and for proceeding to "timed", surgery can be synthesized (Table 1).

Observing patients with type A IMH may be difficult to put into practice in many centers, inasmuch as some regimens require in-hospital observation for at least 30 days. One protocol calls for initial CT and transesophageal echocardiographic studies to rule out PAU, ULP, or AD; daily transthoracic echocardiographic examinations for the following 5 days to monitor for new ULP, aortic insufficiency and enlarging aortic diameter, IMH thickness or pericardial effusion; and follow-up transesophageal echocardiography or CT imaging after 3 days and then weekly through the third week. ${ }^{41}$ Although the risk of progression and adverse events is high early in the course of $\mathrm{IMH},{ }^{47}$ sudden death after 


\section{TABLE 1. Type A IMH criteria}

\begin{tabular}{l} 
Criteria for observation \\
Hemodynamically stable \\
No persistent pain \\
Aortic diameter $\leq 50 \mathrm{~mm}$ \\
Hematoma thickness $\leq 10 \mathrm{~mm}$ \\
No PAU or ULP \\
Small pericardial/pleural effusion and no tamponade \\
No aortic insufficiency \\
Criteria for "timed" intervening surgery \\
Pain \\
New ULP \\
Progression to AD \\
Increasing IMH thickness \\
Increasing aortic diameter \\
Increasing pericardial/pleural effusion or tamponade \\
No regression \\
\hline$M H$, Intramural hematoma; $P A U$, penetrating aortic ulcer; $U L P$, ulcer-like projection;
\end{tabular}

hospital discharge can occur, ${ }^{33}$ and protocols for long-term monitoring are not fully established.

\section{CONCLUSIONS}

AAS refers to a heterogeneous group of conditions that cause a common set of signs and symptoms, the foremost of which is aortic pain, and it subsumes PAU and IMH. Divergent clinical experiences with these entities have led to opposing views of their malignity and, hence, contrasting recommendations for management. Endovascular repair has become the treatment of choice for appropriate PAU cases, and some have cautiously adopted a conservative approach, reserving "timed surgery" for type A IMH.

\section{References}

1. Vilacosta I, San Román JA, Aragoncillo P, Ferreirós J, Mendez R, Graupner C, et al. Penetrating atherosclerotic aortic ulcer: documentation by transesophageal echocardiography. J Am Coll Cardiol. 1998;32:83-9.

2. Vilacosta I, San Román JA. Acute aortic syndrome. Heart. 2001;85:365-8.

3. Hirst AE Jr, Johns VJ Jr, Kime SW Jr. Dissecting aneurysm of the aorta: a review of 505 cases. Medicine (Baltimore). 1958;37:217-79.

4. Shennan T. Dissecting aneurysms. Medical Research Council, Special Report Series, No 193. 1934.

5. Macura KJ, Corl FM, Fishman EK, Bluemke DA. Pathogenesis in acute aortic syndromes: aortic dissection, intramural hematoma, and penetrating atherosclerotic aortic ulcer. AJR Am J Roentgenol. 2003;181:309-16.

6. Vilacosta I, Aragoncillo P, Cañadas V, San Román JA, Ferreirós J, Rodríguez E. Acute aortic syndrome: a new look at an old conundrum. Heart. 2009;95:1130-9.

7. Demers P, Miller DC, Mitchell RS, Kee ST, Chagonjian L, Dake MD. Stent-graft repair of penetrating atherosclerotic ulcers in the descending thoracic aorta: midterm results. Ann Thorac Surg. 2004;77:81-6.

8. Cho KR, Stanson AW, Potter DD, Cherry KJ, Schaff HV, Sundt TM III. Penetrating atherosclerotic ulcer of the descending thoracic aorta and arch. $J$ Thorac Cardiovasc Surg. 2004;127:1393-401.

9. Troxler M, Mavor AID, Homer-Vanniasinkam S. Penetrating atherosclerotic ulcers of the aorta. Br J Surg. 2001;88:1169-77.

10. Coady MA, Rizzo JA, Elefteriades JA. Pathologic variants of thoracic aortic dissections. penetrating atherosclerotic ulcers and intramural hematomas. Cardiol Clin. 1999;17:637-57.
11. Botta L, Buttazzi K, Russo V, Parlapiano M, Gostoli V, Di Bartolomeo R, et al. Endovascular repair for penetrating atherosclerotic ulcers of the descending thoracic aorta: early and mid-term results. Ann Thorac Surg. 2008;85:987-92.

12. Gottardi R, Zimpfer D, Funovics M, Schoder M, Lammer J, Wolner E, et al. Midterm results after endovascular stent-graft placement due to penetrating atherosclerotic ulcers of the thoracic aorta. Eur J Cardiothorac Surg. 2008;33:1019-24.

13. Stanson AW, Kazmier F, Hollier L, Edwards W, Pairolero P, Sheedy P, et al. Penetrating atherosclerotic ulcers of the thoracic aorta: natural history and clinicopathologic correlations. Ann Vasc Surg. 1986;1:15-23.

14. Coady MA, Rizzo JA, Hammond GL, Pierce JG, Kopf GS, Elefteriades JA. Penetrating ulcer of the thoracic aorta: What is it? How do we recognize it? How do we manage it? J Vasc Surg. 1998;27:1006-16.

15. Quint LE, Williams DM, Francis IR, Monaghan HM, Sonnad SS, Patel S, et al. Ulcerlike lesions of the aorta: imaging features and natural history. Radiology. 2001;218:719-23.

16. Harris JA, Bis KG, Glover JL, Bendick PJ, Shetty A, Brown OW. Penetrating atherosclerotic ulcers of the aorta. J Vasc Surg. 1994;19:90-8; discussion 8-9.

17. Litmanovich D, Bankier AA, Cantin L, Raptopoulos V, Boiselle PM. CT and MRI in diseases of the aorta. AJR Am J Roentgenol. 2009;193:928-40.

18. Yoo SM, Lee HY, White CS. MDCT evaluation of acute aortic syndrome. Radiol Clin North Am. 2010;48:67-83.

19. Brinster DR. Endovascular repair of the descending thoracic aorta for penetrating atherosclerotic ulcer disease. J Card Surg. 2009;24:203-8.

20. Hirst AE Jr, Barbour BH. Dissecting aneurysm with hemopericardium: report of a case with healing. $N$ Engl J Med. 1958;258:116-20.

21. MacHaalany J, Yam Y, Ruddy TD, Abraham A, Chen L, Beanlands RS, et al. Potential clinical and economic consequences of noncardiac incidental findings on cardiac computed tomography. J Am Coll Cardiol. 2009;54:1533-41.

22. Lehman SJ, Abbara S, Cury RC, Nagurney JT, Hsu J, Goela A, et al. Significance of cardiac computed tomography incidental findings in acute chest pain. Am J Med. 2009; 122:543-9.

23. Sundt TM. Intramural hematoma and penetrating atherosclerotic ulcer of the aorta. Ann Thorac Surg. 2007;83:S835-41.

24. Hussain S, Glover JL, Bree R, Bendick PJ. Penetrating atherosclerotic ulcers of the thoracic aorta. $J$ Vasc Surg. 1989;9:710-7.

25. Tittle SL, Lynch RJ, Cole PE, Singh HS, Rizzo JA, Kopf GS, et al. Midterm follow-up of penetrating ulcer and intramural hematoma of the aorta. $J$ Thorac Cardiovasc Surg. 2002;123:1051-9.

26. Ganaha F, Miller DC, Sugimoto K, Do YS, Minamiguchi H, Saito H, et al. Prognosis of aortic intramural hematoma with and without penetrating atherosclerotic ulcer: a clinical and radiological analysis. Circulation. 2002;106:342-8.

27. Kaya A, Heijmen RH, Rousseau H, Nienaber CA, Ehrlich M, Amabile P, et al. Emergency treatment of the thoracic aorta: results in 113 consecutive acute patients (the Talent Thoracic Retrospective Registry). Eur J Cardiothorac Surg. 2009;35:276-81.

28. Eggebrecht H, Herold U, Schmermund A, Lind AY, Kuhnt O, Martini S, et al. Endovascular stent-graft treatment of penetrating aortic ulcer: results over a median follow-up of 27 months. Am Heart J. 2006;151:530-6.

29. Krukenberg E. Beiträge zur Frage des Aneurysma dissecans. Beitr Pathol Anat Allg Pathol. 1920;67:329-51.

30. Robbins R, McManus R, Mitchell R, Latter D, Moon M, Olinger G, et al. Management of patients with intramural hematoma of the thoracic aorta. Circulation. 1993;88(5 Pt 2):II1-10.

31. Maraj R, Rerkpattanapipat P, Jacobs LE, Makornwattana P, Kotler MN. Metaanalysis of 143 reported cases of aortic intramural hematoma. Am J Cardiol. 2000;86:664-8.

32. Evangelista A, Mukherjee D, Mehta RH, O'Gara PT, Fattori R, Cooper JV, et al. Acute intramural hematoma of the aorta: a mystery in evolution. Circulation. 2005;111:1063-70.

33. Song J-K, Yim JH, Ahn J-M, Kim D-H, Kang J-W, Lee TY, et al. Outcomes of patients with acute type A aortic intramural hematoma. Circulation. 2009;120: 2046-52.

34. Kan C-B, Chang R-Y, Chang J- P. Optimal initial treatment and clinical outcome of type A aortic intramural hematoma: a clinical review. Eur J Cardiothorac Surg. 2008;33:1002-6.

35. Vilacosta I, San Román JA, Ferreirós J, Aragoncillo P, Méndez R, Castillo JA, et al. Natural history and serial morphology of aortic intramural hematoma: a novel variant of aortic dissection. Am Heart J. 1997;134:495-507.

36. Park K-H, Lim C, Choi JH, Sung K, Kim K, Lee YT, et al. Prevalence of aortic intimal defect in surgically treated acute type A intramural hematoma. Ann Thorac Surg. 2008;86:1494-500. 
37. Lansman SL, McCullough JN, Nguyen KH, Spielvogel D, Klein JJ, Galla JD, et al. Subtypes of acute aortic dissection. Ann Thorac Surg. 1999;67:1975-8.

38. Svensson LG, Labib SB, Eisenhauer AC, Butterly JR. Intimal tear without hematoma: an important variant of aortic dissection that can elude current imaging techniques. Circulation. 1999;99:1331-6.

39. Chirillo F, Salvador L, Bacchion F, Grisolia EF, Valfrè C, Olivari Z. Clinical and anatomical characteristics of subtle-discrete dissection of the ascending aorta. Am J Cardiol. 2007;100:1314-9.

40. Bosma MS, Quint LE, Williams DM, Patel HJ, Jiang Q, Myles JD. Ulcerlike projections developing in noncommunicating aortic dissections: CT findings and natural history. AJR Am J Roentgenol. 2009;193:895-905.

41. KitaiT,KajiS, YamamuroA,TaniT,TamitaK,KinoshitaM,etal.Clinicaloutcomes of medicaltherapyandtimelyoperationininitiallydiagnosedtypeAaorticintramuralhematoma: a 20-yearexperience.Circulation. 2009;120(11 Suppl):S292-8.

42. Pelzel JM, Braverman AC, Hirsch AT, Harris KM. International heterogeneity in diagnostic frequency and clinical outcomes of ascending aortic intramural hematoma. J Am Soc Echocardiogr. 2007;20:1260-8.
43. Song J-K, Kim H-S, Song J-M, Kang D-H, Ha J-W, Rim S-J, et al. Outcomes of medically treated patients with aortic intramural hematoma. Am J Med. 2002;113:181-7.

44. Von Kodolitsch Y, Csosz SK, Koschyk DH, Schalwat I, Loose R, Karck M, et al. Intramural hematoma of the aorta: predictors of progression to dissection and rupture. Circulation. 2003;107:1158-63.

45. Nienaber CA, von Kodolitsch Y, Petersen B, Loose R, Helmchen U, Haverich A et al. Intramural hemorrhage of the thoracic aorta: diagnostic and therapeutic implications. Circulation. 1995;92:1465-72.

46. Shimokawa T, Ozawa N, Takanashi S, Itoh T. Intermediate-term results of surgical treatment of acute intramural hematoma involving the ascending aorta. Ann Thorac Surg. 2008;85:982-6.

47. Estrera A, Miller C III, Lee T-Y, De Rango P, Abdullah S, Walkes J-C, et al. Acute type A intramural hematoma: analysis of current management strategy. Circulation. 2009;120(11 Suppl):S287-91.

48. Kaji S, Akasaka T, Katayama M, Yamamuro A, Yamabe K, Tamita K, et al. Longterm prognosis of patients with type B aortic intramural hematoma. Circulation. 2003; 108:II307-11. 